\title{
COMMENT
}

\section{Ecological value and the US Endangered Species Act: Comment on Waples et al. (2015)}

\author{
Michael Paul Nelson ${ }^{1, *}$, John A. Vucetich ${ }^{2}$, Jeremy T. Bruskotter ${ }^{3}$ \\ ${ }^{1}$ Oregon State University, Department of Forest Ecosystems and Society, Corvallis, OR 97331, USA \\ ${ }^{2}$ Michigan Technological University, School of Forest Resources and Environmental Sciences, Houghton, MI 49931, USA \\ ${ }^{3}$ The Ohio State University, The School of Environment and Natural Resources, Columbus, OH 43210, USA
}

\begin{abstract}
The US Fish and Wildlife Service and National Marine Fisheries Service (the Services) have struggled to understand the meaning of the definition of 'endangered species' within the Endangered Species Act (ESA) of 1973. This struggle centers on how the Services should interpret the phrase 'significant portion of its range' (SPOIR), which is part of the definition of an 'endangered species' in the ESA. The same issue has been debated by conservation scholars for more than a decade. Waples et al. (2015; Endang Species Res 27:189-192) offer a defense of the Services' policy and their interpretation of the SPOIR phrase (issued in July 2014: 79 Fed. Reg. 37578). In doing so they criticize an alternative position that we, and others, have presented. We are concerned that Waples et al. (2015) inaccurately characterize our position and fail to acknowledge existing scholarship conflicting with their position. More generally, the policy designed and defended by Waples et al. (2015) and colleagues, and issued by the Services, is inconsistent with Congressional intent, and essentially the same position that has been roundly rejected in several federal court decisions.
\end{abstract}

KEY WORDS: Endangered species - Species recovery $\cdot$ Species range $\cdot$ Species extinction Ecological value

Waples et al. (2015) critique a position about the legal interpretation of 'endangered species,' as that concept applies to the US Endangered Species Act (ESA) of 1973. This position was developed by us, and others, over a series of articles (Vucetich et al. 2006, Tadano 2007, D'Elia et al. 2008, Bruskotter \& Enzler 2009, Enzler \& Bruskotter 2009, Greenwald 2009, Carroll et al. 2010, Kamel 2010) and was subsequently shared in venues with broader audiences (Nelson \& Vucetich 2014, 2015, Vucetich \& Nelson 2014). The critique by Waples et al. $(2015$, p. 191) is based on characterizing our position as: '[T]hey [Vucetich \& Nelson (2014)] argued that a goal more commensurate with Congress's intent in passing the

${ }^{*}$ Corresponding author: mpnelson@oregonstate.edu
ESA would be to restore species to all portions of their historic range that are suitable or can be made suitable...' [italics added]. See Appendix 1 for an explanation of how this does not represent our view.

Our position, summarized in 4 points, has been and continues to be: (1) A species is recovered when it no longer fits the legal definition of an endangered species, i.e. when it is not 'in danger of extinction throughout all or a significant portion of its range' and the species is unlikely to fit the definition in the foreseeable future. (Note: The quoted text is the legal definition that is specified in the ESA). (2) That legal definition means the purpose of the ESA has at least some restorative mandate beyond merely ensuring

() The authors 2016. Open Access under Creative Commons by Attribution Licence. Use, distribution and reproduction are unrestricted. Authors and original publication must be credited. 
that a species is not 'at risk of extinction.' (3) Recovery likely requires a species to occupy much or most of its historic range that is currently suitable or can be made suitable by removing or sufficiently mitigating threats to the species (how much depends, in part, on how one interprets the term 'significant'). (4) Our position is consistent with prior court rulings and congressional intent (see 3 paragraphs below). Thus, there is a discrepancy between what we have written (Vucetich et al. 2006, Nelson et al. 2007, Vucetich \& Nelson 2014) and the representation of our position by Waples et al. (2015).

We are also concerned that a reader of Waples et al. (2015) would think that our position is essentially anthropocentric. Waples et al. (2015, p. 190) write that '[t]he main difference between our framework and the vision of Vucetich \& Nelson is the point of reference for evaluating significance: they focus on importance to humans, whereas our framework emphasizes importance to the species itself.' The same claim of anthropocentrism was made by Waples et al. (2007). In contrast to their 2015 publication, Waples et al. (2007) provided reasoning for their claim, and we responded by demonstrating why our position could not be interpreted as anthropocentric (see Nelson et al. 2007, p. 1647, column 1). Furthermore, anthropocentrism is incongruous with the corpus of our scholarship (e.g. Vucetich \& Nelson 2010, Vucetich et al. 2015).

Waples et al. (2015, p. 190) assert the objectivity of their position when they write: 'Although our framework can be challenging to apply, it is objective and conceptually simple and should help promote consistency and predictability, exactly as a policy should'. Describing the condition of a species, including its risk of extinction is a largely objective endeavor (i.e. free of normative elements). However, judging whether that condition constitutes endangerment is fundamentally normative (i.e. requiring a value judgment); no framework can escape that circumstance. Moreover, the inherently normative nature of determining whether a species is endangered is well understood. For example, Freyfogle \& Goble (2009, p. 242) explain how deciding endangerment requires answering 'two distinctly different questions.' The first question, one that can be answered objectively by science, is 'What is the probability that a species will become extinct in some period of time?'; in contrast, the second question (i.e. 'Is that risk acceptable?') cannot be objectively answered by science; it is normative, premised upon a value judgment. Our concern, articulated elsewhere (e.g. Nelson et al. 2007), is that the interpretation of SPOIR described in
Waples et al. (2015) fails to recognize this normative dimension.

We are also concerned with Waples et al.'s (2015) portrayal of the process leading to the approval of the final policy. The policy Waples et al. (2015) refer to interprets the phrase 'significant portion of its range' (SPOIR). Waples et al. (2015, p. 190) state: '... two and a half years later, following an extensive public comment period, the policy was finalized (FWS \& NMFS 2014).' We maintain and have argued elsewhere that this policy is inappropriate in spite of being finalized after an 'extensive public comment period' (Bruskotter et al. 2014, Nelson \& Vucetich 2014, 2015, Vucetich \& Nelson 2014). Waples et al. (2015) also do not mention that this policy formalized SPOIR interpretations frequently rejected by federal courts as inconsistent with the ESA (e.g. Enzler \& Bruskotter 2009). In fact, the most recent court to examine the FWS's interpretation of the SPOIR phrase (Humane Society of the United States et al. v. Jewell, Civil Action No. 13-186 [BAH], D.C. Cir. 2014), much like previous court decisions, concludes that the FWS's reasoning, as it relates to SPOIR, is an 'inherent fallacy' and 'runs counter to congressional intent.' Waples et al. (2015) also refer to the public comment process as a means of partially justifying the FWS policy. However, they do not mention the fact that more than 4 in 5 comments ( 88\%) expressed opposition to at least some part of the policy, while only $4 \%$ supported it outright (see Appendix 2).

With respect to interpreting the legal definition of an endangered species, Waples et al. (2015, p. 191) write: 'Guessing the motivations and intent of Congress in passing legislation is tricky, and reasonable people can come to very different conclusions.' While congressional intent can be difficult to infer on some instances, considerable evidence, presented elsewhere (e.g. House Report No. 93-412 [1973], House Report No. 95-1625 [1978], Enzler \& Bruskotter 2009), indicates that congressional intent is reliably inferred in this instance. For example, when Congress amended the ESA in 1978, the House provided explicit discussion of Congress's understanding of the term 'range'. In contrast to Waples et al. (2015) and the FWS's policy, the report notes that '[t]he term 'range' is used in the general sense and refers to the historical range of the species' (House Report No. 951625 [1978], p. 18, italics added).

Finally, we agree with Waples et al. (2015, p. 191) when they write: 'It [The ESA] is about conserving threatened and endangered species and the ecosystems those species require (Ashe \& Sobeck 2014).' It is also important to know why, according to the 
ESA, we should conserve threatened and endangered species and their requisite ecosystems: 'The Congress finds and declares that-various species of fish, wildlife, and plants...are of esthetic, ecological [value], educational, historical, recreational, and scientific value to the Nation and its people...' (ESA 1973, Congressional findings and declaration of purposes and policy, 16 U.S.C 1531 [a][3] [1973], italics added). If a reason to protect a species is their ecological value, then rudimentary logic dictates that any particular species should be conserved and protected across much of its former range and at densities allowing the species to perform its ecological function.

Our primary concern with Waples et al. (2015), and by extension the new FWS policy they acknowledge they are architects of, is that both fail to meet the mandate of the ESA. In fact, we find their position, and by extension the new FWS policy (FWS \& NMFS 2014) to be fundamentally inconsistent with the ESA (Nelson \& Vucetich 2014, 2015, Vucetich \& Nelson 2014).

\section{LITERATURE CITED}

Ashe D, Sobeck E (2014) Using scarce resources to save endangered species. The New York Times, 4 September 2014. www.nytimes.com/2014/09/05/opinion/usingscarce-resources-to-save-endangered-species.html

Bruskotter JT, Enzler SA (2009) Narrowing the definition of endangered species: implications of the US Government's interpretation of the phrase 'a significant portion of its range' under the Endangered Species Act of 1973. Hum Dimens Wildl 14:73-88

Bruskotter JT, Vucetich JA, Enzler S, Treves A, Nelson MP (2014) Removing protections for wolves and the future of the US Endangered Species Act (1973). Conserv Lett 7: 401-407

Carroll C, Vucetich JA, Nelson MP, Rohlf DJ, Phillips MK (2010) Geography and recovery under the US Endangered Species Act. Conserv Biol 24:395-403

Cohen J (1960) A coefficient of agreement for nominal scales. Educ Psychol Meas 20:37-46

Cohen J (1968) Weighted kappa: nominal scale agreement with provision for scaled disagreement or partial credit. Psychol Bull 70:213-220

D'Elia J, Zwartjes M, McCarthy S (2008) Considering legal viability and societal values when deciding what to conserve under the U.S. Endangered Species Act. Conserv Biol 22:1072-1074

Enzler SA, Bruskotter JT (2009) Contested definitions of endangered species: the controversy regarding how to interpret the phrase 'a significant portion of a species range'. Va Environ Law J 27:1-65

ESA (1973) Endangered Species Act of 1973. Title 16 United States Code, Sections 1531-1544

Freyfogle ET, Goble DD (2009) Wildlife law: a primer. Island Press, Washington, DC

FWS and NMFS (Fish and Wildlife Service and National Marine Fisheries Service) (2014) Final policy on interpretation of the phrase 'significant portion of its range' in the Endangered Species Act's definitions of 'endangered species' and 'threatened species'. Fed Regist 79: 37578-37612

Greenwald DN (2009) Effects on species' conservation of reinterpreting the phrase 'significant portion of its range' in the US Endangered Species Act. Conserv Biol 23: 1374-1377

Kamel A (2010) Size, biology, and culture: persistence as an indicator of significant portions of range under the Endangered Species Act. Ecol Law Q 37:525-561

Landis JR, Koch GG (1977) The measurement of observer agreement for categorical data. Biometrics 33:159-174

Lombard M, Snyder-Duch J, Bracken CC (2002) Content analysis in mass communication: assessment and reporting of intercoder reliability. Hum Comm Res 28:587-604

Nelson MP, Vucetich JA (2014) The future of conservation and the tragedy of triage. The Huffington Post, 23 Nov 2014. www.huffingtonpost.com/michael-p-nelson/thefuture-of-conservatio_b_5870568.html

Nelson MP, Vucetich JA (2015) Triumph, not triage. Environ Forum (Washington DC) 32:32-35

Nelson MP, Vucetich JA, Phillips MK (2007) Normativity and the meaning of endangered: Response to Waples et al. 2007. Conserv Biol 21:1646-1648

Tadano NM (2007) Piecemeal delisting: designating distinct population segments for the purpose of delisting gray wolf populations is arbitrary and capricious. Wash Law Rev 82:795-823

> Vucetich JA, Nelson MP (2010) Sustainability: virtuous or vulgar? Bioscience 60:539-544

Vucetich JA, Nelson MP (2014) Conservation, or curation? The New York Times, 21 August 2014. www.nytimes. com/2014/08/21/opinion/conservation-or-curation.html? r $=0$

Vucetich JA, Nelson MP, Phillips MK (2006) The normative dimension and legal meaning of endangered and recovery in the U.S. Endangered Species Act. Conserv Biol 20: 1383-1390

> Vucetich JA, Bruskotter JT, Nelson MP (2015) Evaluating whether nature's intrinsic value is an axiom of or anathema to conservation. Conserv Biol 29:321-332

Waples RS, Adams PB, Bohnsack J, Taylor BL (2007) A biological framework for evaluating whether a species is threatened or endangered in a significant portion of its range. Conserv Biol 21:964-974

> Waples RS, Adams PB, Bohnsack JA, Taylor BL (2015) When is a species at risk in 'all or a significant portion of its range'? Endang Species Res 27:189-192 
Appendix 1. Summarizing our view on 'range'

Given what we believe to be confusion over our view, as expressed in Vucetich \& Nelson (2014), we clarify it here. Early in Vucetich \& Nelson (2014) we write, [1] 'The law says that a species qualifies for protection if it in danger of extinction "throughout all or a significant portion of its range." But what is "significant"? And how is "range" defined? Now, under a policy that took effect July 31, the agency has provided answers.' What follows in Vucetich \& Nelson (2014) is a lengthy critique of the FWS's new interpretation of the term 'range' (an interpretation championed by Waples et al. 2015), with explicit reasoning as to why the FWS's interpretation is inconsistent with the broad purpose of the ESA. At the end of that critique we write: [2] 'A more appropriate interpretation of range would be those portions of a species' historical distribution that are suitable, or that can feasibly be made suitable, by mitigating or removing the threats that had caused the species' decline' [italics added].

Waples et al. (2015, p. 191) wrote: [3] 'They [Vucetich \& Nelson 2014] argued that a goal more commensurate with Congress's intent in passing the ESA would be to restore species to all portions of their historic range that are suitable or can be made suitable... .' Importantly, our conclusion (i.e. Quote 2) is not, by itself, a claim about the meaning of the legal definition of endangered species. Rather, this sentence is a claim about the interpretation of the word 'range' as it operates within the legal definition of endangered species. Consequently, it would not be reasonable to conclude that our view is represented by the statement that a species is endangered unless it is restored to all portions of its historic range that are suitable or can be made suitable (Vucetich et al. 2006).

It is pertinent that the interpretation of range expressed in Quote (2) is also offered verbatim in Vucetich et al. (2006) in a section of that paper entitled 'The Meaning of Range,' where we provide a thorough justification for this interpretation of range and how this interpretation of range influences the meaning of the legal definition of endangered species. It is important to know that Quote (3) does not represent our view.

Appendix 2. Analysis of public comments about the US Fish \& Wildlife Service's (USFWS) proposed policy on interpretation of the phrase 'significant portion of its range' (SPOIR)

We randomly sampled 219 of 503 public comments submitted to the USFWS in reference to this policy change (http://www. regulations.gov/\#!docketDetail;D=FWS-R9-ES-2011-0031) and coded these comments with regard to their level of agreement with the proposed SPOIR policy. Sample size was selected to provide a $\pm 5 \%$ margin of error at the $95 \%$ confidence level. Two coders independently coded the comments into 4 categories reflecting support and opposition to the SPOIR policy: (1) supportive, (2) supportive in part, oppose in part, (3) oppose, and (4) indeterminable (i.e. we cannot tell if they support or oppose in part or in whole).

In order to assess the reliability of codes, $\sim 40 \%$ of the comments (87 of 219) were coded by both coders (i.e. 1 coder assessed 150 comments, the other 156 comments). We assessed inter-rater reliability using Cohen's Kappa ( $\kappa)$ (Cohen 1960, 1968). The cut-off point for an acceptable $\kappa$ value is a matter of professional judgment; $\kappa \geq 0.6$ is generally acceptable for exploratory research and represents a substantial level of agreement above chance (Lombard et al. 2002). $\kappa>0.8$ is considered almost perfect (Landis \& Koch 1977). After an initial assessment, coders re-evaluated comments where there was disagreement. Initially, agreement was $87 \%(\kappa=0.722)$; after re-assessment, agreement rose to $97 \%(=0.931)$.

We found that $\sim 4 \%$ of the sampled public comments expressed support for the SPOIR policy, $16 \%$ expressed support for some element of the policy while opposing other elements, and $72 \%$ expressed opposition to the policy. The rest were indeterminable.

Editorial responsibility: Brendan Godley, University of Exeter, Cornwall Campus, UK
Submitted: January 25, 2016; Accepted: May 12, 2016

Proofs received from author(s): May 24, 2016 